\title{
THE ANTIBACTERIAL EFFECT OF WATER-SOLUBLE COMPOUNDS FROM AUTOXIDISING LINOLENIC ACID
}

\author{
J. M. C. GutTeridge, P. Lamport and T. L. Dormandy \\ Departments of Chemical Pathology and Microbiology, Whittington Hospital, \\ London, N19 5NF
}

\begin{abstract}
Plate VI
IN a previous paper we suggested that the antibacterial properties of unsaturated long-chain fatty acids could be partly due to the presence of autoxidation products (Gutteridge, Lamport and Dormandy, 1974). When unsaturated fatty acids are allowed to autoxidise in aqueous dispersion, many secondary fragmentation products go into solution. The exact nature of most of these compounds is not known, but many have been shown to be peroxidic or aldehydic (Schauenstein, 1967). One of them, malonyldialdehyde (MDA), forms a distinctive colour complex with thiobarbituric acid (TBA) and has been widely used as a measure of lipid autoxidation (Slater, 1972; Stocks et al., 1972). More recently, biological properties have been ascribed to this compound in its own right (Chio and Tappel, 1969; Stossel, Mason and Smith, 1974). This paper describes the separation, by thin-layer chromatography, of the water-soluble autoxidation products of linolenic acid according to their reaction with Schiff's aldehyde reagent. The antibacterial activities of these fractions have been compared with those of aldehyde standards.
\end{abstract}

\section{MATERIAL AND METHODS}

Lipid autoxidation products were prepared as previously described (Gutteridge, Stocks and Dormandy, 1974). A dispersion of $5 \mathrm{~g}$ of linolenic acid $(99 \%$ pure, Koch-Light Ltd,

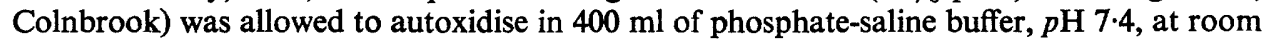
temperature under normal laboratory lighting for four days. Rancid lipid was removed by filtration and the resulting clear aqueous filtrate was extracted first with $400 \mathrm{ml}$ of chloroform (Analar, BDH Ltd, Poole) then with $400 \mathrm{ml}$ of diethylether (Analar, BDH Ltd). The combined solvent phases containing the autoxidation products were pooled for rotary vacuum evaporation at $40^{\circ} \mathrm{C}$. The residue weighing $1.7 \mathrm{~g}$ was dissolved in $1 \mathrm{ml}$ of chloroform, which was then applied to four $20 \times 20 \mathrm{~cm}$ fibreglass silica-gel thin-layer-chromatography sheets (ITLC-SAF, Gelman Hawksley Ltd, Lancing). The chromatograms were developed in the solvent system hexane, diethylether, butanol, ethanol $(60: 40: 1: 1)$. Compounds were located by cutting a $5-\mathrm{cm}$ strip from the side of each chromatogram and spraying with Schiff's aldehyde reagent (BDH Ltd). For location of lipid peroxides a $5-\mathrm{cm}$ strip was sprayed with a solution containing equal volumes of ethanolic guaiacum $1.5 \%(\mathrm{w} / \mathrm{v})$ and peroxidase RZ. 1 (Hughes \& Hughes Ltd, Romford) $0.02 \%(\mathrm{w} / \mathrm{v})$ in acetate buffer $p \mathrm{H} 6.0$. The various Schiff-reacting zones were cut out and eluted three times with $10 \mathrm{ml}$ of solvent. Three solvents - ether, chloroform, and ethanol-were used for sequential extraction. The pooled solvent phases were evaporated to dryness at $40^{\circ} \mathrm{C}$ in a rotary vacuum evaporator and the residue was dissolved in $1 \mathrm{ml}$ of chloroform for testing against bacteria. Each fraction was also tested for MDA with the TBA reagent (Gutteridge, Stocks and Dormandy, 1974).

The antibacterial activity of each fraction was tested against the following organisms: Staphylococcus aureus (Oxford strain) no. NCTC6571, Escherichia coli no. NCTC10418 and

Received 20 June 1975; accepted 3 Sept. 1975.

J. MED MICROBIOL.-VOL. 9 (1976) 
hospital wild strains of Staph. aureus, Staph. albus, Streptococcus faecalis, streptococcus group C, Bacillus sp., Klebsiella aerogenes, Pseudomonas aeruginosa, Corynebacterium sp. (a diphtheroid organism), Bacteroides sp., and Clostridium welchii. C. welchii, was grown on Wellcotest sensitivity-test agar (Wellcome Reagents, Beckenham) by anaerobic incubation, and Bacteroides was grown anaerobically on Wellcotest agar with the addition of defibrinated horse-blood $7 \%(\mathrm{v} / \mathrm{v})$. All other organisms were grown aerobically on Wellcotest agar. All incubation was at $37^{\circ} \mathrm{C}$ for $18 \mathrm{~h}$.

For disk-diffusion tests, growth from overnight blood-agar cultures was used for the preparation of saline suspensions. These were inoculated on to the appropriate test plates with a sterile wet swab, to give a semi-confluent growth of organisms. The $10-\mathrm{mm}$ disks were made from blotting paper; each contained $20 \mu \mathrm{l}$ of a Schiff-reacting fraction. The chloroform solvent was allowed to evaporate completely before the disks were applied to the surface of the plate. The diameters of zones of inhibition, measured after incubation for $18 \mathrm{~h}$, included the diameter of the disk.

For sensitivity tests in tubes without culture media the suspension of Oxford Staph. aureus was washed three times with sterile phosphate buffer, $p \mathrm{H} 7 \cdot 4$, and deposited by centrifugation at 3000 r.p.m. for 30 min. each time. The final deposit was used to prepare suspensions of the organism standardised against Brown's Opacity Tube no. 2. This suspension was then diluted in buffer to give a final concentration of $c .12 \times 10^{6}$ organisms per ml. Surface counts were performed on the test suspension immediately before use to determine the number of viable organisms.

Two aldehyde standards, MDA and hydroxypentenal (HPE), characterictic of those formed during lipid autoxidation, were also tested for antibacterial activity. MDA was compared with the well-known sporicidal chemical, glutaryldialdehyde (GDA), a fivecarbon-atom-molecule belonging to the same chemical series but not, so far as is known, a lipid-autoxidation product. Hydroxypentenal is an unsaturated hydroxyaldehyde; it represents an active class of compounds isolated from autoxidising fatty acids and possesses cytoxic properties (Schauenstein, 1967). MDA was prepared from 1,1,3,3-tetramethoxypropane (Kodak Ltd) by the method of Saslaw and Waravdekar (1957). Its concentration was measured and calculated as described by Sinnhuber and Yu (1958). Glutaryldialdehyde was obtained commercially as buffered Cidex (Ethicon Ltd, Edinburgh). The HPE was synthetised by Dr W. White of Brunel University.

Reduced glutathione (GSH) combines with reactive aldehyde groups to form an adduct. As a test of its inhibitory properties on the autoxidation fractions, $20 \mu \mathrm{l}$ of an aqueous solution containing GSH $200 \mathrm{~m}$. mole per litre was freeze-dried on 10-mm disks; $20 \mu \mathrm{l}$ of the Schiff fractions were then added. The chloroform was allowed to evaporate and the disks were allowed to stand for $15 \mathrm{~min}$. at room temperature before they were applied to the surface of the plate.

Gas-liquid chromatography was performed on a Pye 104, Model 64 chromatograph with flame-ionisation detectors. The columns were glass $1.5 \mathrm{~m} \times 4.0 \mathrm{~mm}$ (internal diameter) packed with $10 \%$ polyethylene glycol $20 \mathrm{M}$ stationary phase on Diatomite CAW (Pye Unicam Ltd, Cambridge). The temperature was held at $160^{\circ} \mathrm{C}$ for $10 \mathrm{~min}$. after injection of the sample, then increased by $7^{\circ} \mathrm{C}$ per min. until $230^{\circ} \mathrm{C}$ was reached and maintained until the last peak emerged. Detector temperature was maintained at $230^{\circ} \mathrm{C}$. Injected samples were dissolved in chloroform. Nitrogen and hydrogen flow rates were $45 \mathrm{ml}$ per min.

\section{RESULTS}

The results confirm that the complex mixture of water-soluble aldehydic and peroxidic compounds formed during fatty-acid autoxidation possess selective antibacterial properties.

\section{Bacterial sensitivity to autoxidation fractions}

The table summarises the sensitivities of the various organisms to the Schiff fractions, and the TBA reactivity of the fractions expressed as $\mathrm{m}$. moles of MDA per litre. Of the 


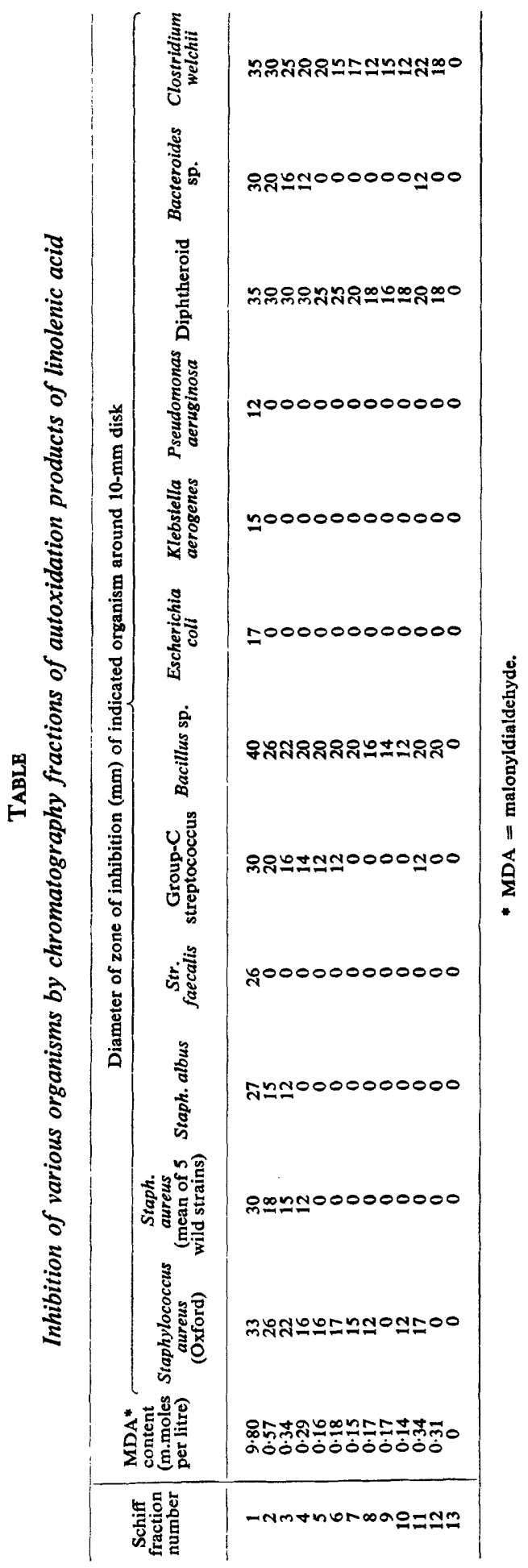


various organisms grown on Wellcotest Agar, Bacillus sp., group-C streptococci, diphtheroids, C. welchii, and the Oxford strain of Staph. aureus were particularly sensitive to inhibition by the Schiff fractions, whereas $P$. aeruginosa, Str. faecalis, $E$. coli and $K$. aerogenes were insensitive.

The results suggest that for the sensitive bacteria the antibacterial effect is related to the TBA-reactivity of the fractions. Against the Oxford strain of Staph. aureus, GSH completely blocked the inhibitory activity of all fractions except that of fraction no. 1, whose inhibitory property remained unchanged.

\section{The activity of aldehyde standards}

Neither MDA or GDA was active against the Oxford strain of Staph. aureus, when tested in disks containing $20 \mu \mathrm{l}$ of solutions ranging from 1 to $200 \mathrm{~m}$.moles per litre. The compound HPE did, however, produce a $20-\mathrm{mm}$ zone of inhibition against the Oxford strain of Staph. aureus when $20 \mu \mathrm{l}$ of a $140 \mathrm{~m}$.moles per litre solution was contained in a disk; this activity could be abolished by adding the HPE to a disk previously impregnated with $20 \mu$ l of GSH 200 m.moles per litre.

When GDA and MDA were incubated for $1 \mathrm{~h}$ at $28^{\circ} \mathrm{C}$ in a test tube in the absence of culture medium with the washed suspension of the Oxford strain of Staph. aureus, both compounds were antibacterial. This activity was $p \mathrm{H}$-dependent. GDA 2 m.moles per litre buffered to $p \mathrm{H} 7.5$ killed the Oxford strain of Staph. aureus, $12 \times 10^{6}$ viable cells per $\mathrm{ml}$, completely; MDA $2.5 \mathrm{~m}$.moles per litre killed the Oxford strain of Staph. aureus, $12 \times 10^{6}$ cells per ml, when buffered to $p \mathrm{H} 5 \cdot 5$. MDA was not antibacterial at either $p \mathrm{H} \mathrm{7.0}$ or 9.0 at this concentration. Acidification to $p \mathrm{H} 5.5$ alone had no effect.

\section{Chromatographic separation of autoxidation products}

The specific location of lipid peroxides on the thin-layer chromatogram showed these to be present in Schiff fractions no. 1, 5, 6, 7, 11, and 13; by far the most reactive was no. 1 .

Of the 13 TLC bands that reacted with the Schiff's aldehyde reagent, 12 were TBAreactive, with the highest reactivity in fraction no. 1 .

When the individual Schiff fractions were separated by gas-liquid chromatography, each showed many peaks with no single compound predominant. The gas-liquid chromatogram (fig.) illustrated the complexity of the solvent extract before TLC separation into Schiff fractions.

\section{Discussion}

It has long been known that autoxidising lipids generate many low-molecular-weight, relatively polar compounds; but, for technical and other reasons, they have received relatively little attention until recent years. They have now been shown to possess cytotoxic and prostaglandin-like activity (Schauenstein, 1967; Baker and Wilson, 1966; Dakhil and Vogt, 1961; Gutteridge, 1975a), to include enzyme inhibitors (Wills, 1961) and to have a striking effect on various stages of intrinsic plasma coagulation (Barrowcliffe, Gutteridge and Dormandy, 1975). The findings reported in the present paper confirm the antibacterial activity of autoxidising linolenic acid (Gutteridge, Lamport and Dormandy, 1974), and strongly suggest that this property is a function of aldehydic rather than of peroxidic intermediates. In particular, there was close parallelism between the antibacterial potency of the Schiff fractions and their TBA reactivity. By contrast, only in two fractions was antibacterial activity related to the concentration of peroxidase-labile compounds. Of these two fractions, no. 1 remains a highly concentrated and complex mixture that requires more study. The aldehydic nature of the antibacterial compounds is further supported by the effect of GSH on their antibacterial activity. The protection afforded by GSH could be explained in at least two ways: (1) GSH may protect the functional sulphydryl groups of enzymes which are particularly susceptible to inhibition by aldehydes formed during autoxidation 
ANTIBACTERIAL ACTIVITY OF FATTY ACIDS

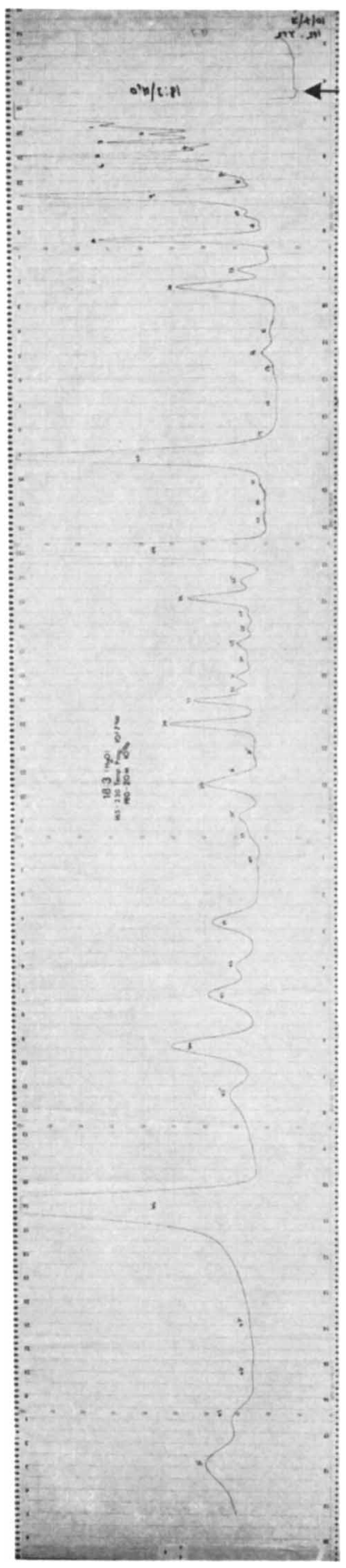

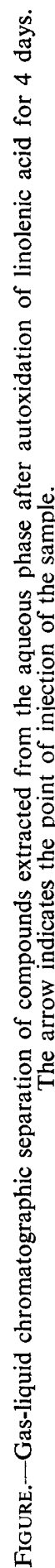


(Schauenstein, 1967); and (2) the interaction of these aldehydes with GSH on the paper disks might prevent or delay their penetration into the bacterial cells.

Paradoxically, the antibacterial activity of MDA, the most extensively studied autoxidation product, remains in doubt, In this connection, two important distinctions must be made: (1) various " pure" MDA standards must be distinguished from other autoxidation products that give an MDA-like colour reaction; and (2) the presence or absence of protein in the bacterial culture must be specified. Pure MDA standards-e.g., freshly hydrolysed 1,1,3,3-tetramethoxypropane-have a somewhat weak antibacterial activity and even this is abolished by the addition of proteins. In some reported experiments, moreover, it is not clear how far the effect of methanol in the standards had been taken into account. This relative inefficacy of pure MDA may be related to its tendency to form stable complexes with proteins and other nitrogenous substances (Chio and Tappel, 1969). The autoxidation products in the Schiff fractions described in the present paper do not include MDA proper; it is too volatile to be recovered by solvent extraction (Gutteridge, 1975b). The MDA-like colour reaction of the fractions must be ascribed to intermediate products, which break down to MDA during the acid-hydrolysis stage of the TBA assay (Gutteridge, Stocks and Dormandy, 1974). It is these unstable MDA precursors that are strongly antibacterial; and they are active in the presence and in the absence of proteins. The only one of these precursors that has so far been tested by us in a pure state is the unsaturated hydroxyaldehyde HPE; it was antibacterial. The mode of action of these unstable autoxidation products remains uncertain, but their remarkable potency in various biological systems may actually depend on their instability. The initial lipid autoxidation is a free-radical reaction; and reactive free-radical intermediates may also be generated in the process of secondary fragmentation.

\section{SUMMARY}

Compounds extracted from the aqueous phase of an autoxidising linolenic acid-buffer dispersion possess selective antibacterial properties. Experimental evidence suggests that these activities are in part a function of the aldehydic intermediates.

We are grateful to Professor T. F. Slater of Brunel University for the gift of hydroxypentenal, to the Wellcome Trust for financial assistance, and to $\mathrm{Mr} \mathrm{S}$. Stavrinou for photographic advice.

\section{REFERENCES}

BAKER, N. AND WILSON, L. 1966. Water-soluble inhibitor(s) of tumor respiration formed from ultraviolet-induced oxidation of linoleic and linolenic acids. J. Lipid Res., 7, 349.

Barrowcliffe, T. W., GutTeridge, J. M. C. AND Dormandy, T. L. 1975. The effect of fatty-acid autoxidation products on blood coagulation. Thrombos. Diathes. Haemorrh., 33, 271.

CHIO, K. S. AND TAPPEL, A. L. 1969. Inactivation of ribonuclease and other enzymes by peroxidizing lipids and by malonaldehyde. Biochemistry, N.Y., 8, 2827.

DAKHIL, T. AND VoGT, W. 1962. Hydroperoxides, the active principles of poly-unsaturated fatty-acid preparations which cause intestinal muscle to contract. J. Physiol., 160, 21P.

GUTTERIDGE, J. M. C. 1975a. Consequences of lipid autoxidation in biological materials. $\mathrm{Ph} . \mathrm{D}$. Thesis, University of London.

GutTeridge, J. M. C. $1975 b$. The use of standards for malonyldialdehyde. Analyt. Biochem., In the press.

GutTeridge, J. M. C., Lamport, P. AND Dormandy, T. L. 1974. Autoxidation as a cause of antibacterial activity in unsaturated fatty acids. J. med. Microbiol., 7, 387.

GutTeridge, J. M. C., Stocks, J. AND Dormandy, T. L. 1974. Thiobarbituric acid reacting substances derived from autoxidising linoleic and linolenic acids. Analyt. chim. Acta., $70,107$.

SASLAw, L. D. AND WARAVDEKar, V. S. 1957. Preparation of malonaldehyde bis-bisulphite sodium salt. J. organ. Chem., $22,843$. 
SCHAuENSTRIN, E. 1967. Autoxidation of polyunsaturated esters in water: chemical structure and biological activity of the products. J. Lipid Res., 8, 417.

SinNHUBER, R. O. AND YU T. C. 1958. 2-Thiobarbituric acid method for the measurement of rancidity in fishery products. Food Technol., 12, 9.

Slater, T. F. 1972. Free radical mechanisms in tissue injury, London, p. 34.

Stocks, J., Offerman, E. L., Modell, C. B. ANd Dormandy, T. L. (1972). The susceptibility to autoxidation of human red cell lipids in health and disease. Br. J. Haematol., 23, 713.

Stossel, T. P., Mason, R. J. AND SmITH, A. L. 1974. Lipid peroxidation by human blood phagocytes. J. clin. Invest., 54, 638.

WILLS, E. D. 1961. Effect of unsaturated fatty acids and their peroxides on enzymes. Biochem. Pharmac., 7, 7. 